\title{
Farm technical efficiency under a tradable milk quota system
}

\author{
F. J. Areal, ${ }^{1}$ R. Tiffin, and K. Balcombe \\ Agricultural and Food Economics Department, The University of Reading, PO Box 237, Reading, United Kingdom, RG6 6AR
}

\begin{abstract}
This paper incorporates the milk quota system into technical efficiency analysis of dairy farms in England and Wales. Our approach accounts for milk quota trade, allowing an investigation of the relationship between the way in which milk quota market is used by farmers and technical efficiency. In addition, several explanatory variables for inefficiency were used. Results obtained from a Bayesian stochastic frontier analysis show that the way in which farmers use the milk quota market is linked to farm efficiency. Other aspects such as environmental payments received by the farmer are linked to inefficiency.
\end{abstract}

Key words: technical efficiency, milk quota, Bayesian stochastic frontier

\section{INTRODUCTION}

The abolition of the dairy quota regimen in the European Union (EU) by March 31, 2015, will be the end of a policy that started in 1984 as a way to reduce the increasing EU common agricultural policy's (CAP) budget cost. The abolition of milk quotas, which is in concordance with World Trade Organization liberalization process, will expose EU farmers to international market competition, meaning an increase in milk production associated with raw milk price cuts. Under the new scenario, only the most efficient producers will have the chance to remain in business. Therefore, it is relevant, particularly for policy makers, to understand how the use of the quota market and its abolition may affect farm technical efficiency. Specifically, it helps policy makers to support those inefficient farms by identifying where inefficiencies arise as well as the drivers behind inefficiency.

The associated effects of quota regimens in the short and long run at the market (e.g., welfare changes, market inefficiency) and farm levels (e.g., higher average costs, farm inefficiency) using comparative static analysis were highlighted by Dawson (1991) and Van Kooten and Spriggs (1984). Dawson (1991) noted that the economic

Received June 20, 2011.

Accepted September 9, 2011.

${ }^{1}$ Corresponding author: f.j.areal@reading.ac.uk rent of quota (i.e., the difference between the milk price under the quota system and the competitive market price times the milk quota) will be used by efficient producers to acquire quotas from inefficient producers if quota trade is permitted. The introduction of a milk quota system affects farm and milk market efficiency by reducing the output of farms. In the early stages of the introduction of the quota system, UK milk production was reduced by culling cows and reducing concentrate feeding or by throwing milk down the drain (Harvey, 1985). Under a fixed milk quota system, where trading quota is not permitted, technical improvements, and structural change would be constrained. Under a more flexible system that allowed transferring milk quota it would be expected that efficient farmers would expand their business at the expense of less efficient farmers.

The introduction of a milk quota system has accelerated the changes in milk production in England and Wales. The dairy herd has suffered approximately a $40 \%$ decrease in the last few decades, from approximately 3,480,000 dairy cows in 1973 to approximately $2,090,000$ in 2005 (Defra, 2011). This decrease in dairy cow numbers has been further pronounced since 1984, the year in which the quota system was put in place. Between 1973 and 1983 (i.e., before the introduction of the quota system), the decline in the dairy herd numbers was approximately 5\%, whereas from 1984 to 2005, the dairy herd numbers plummeted by $37 \%$. Despite this decrease in the dairy herd, the level of production has not been affected because of an increase in the milk yield per cow, which greatly increased in the 1990s. The number of dairy farms has also suffered a large cut in England and Wales. The number of holdings decreased from 28,093 in 1995 to 12,867 in 2007 , a $54 \%$ reduction. However, holdings structure has adapted by increasing the number of cows per holding. Thus, the average herd size in England and Wales has increased from 76 in 1996 to 97 in 2004. Milk deliveries have passed from being over quota in the 1990s to being under quota during recent years, especially during 2007 and 2008, when the milk delivery reached 744 million liters under the 14,139 million liters of quota. This may leave room for efficient farmers to go over quota without being fined because the system allows farmers to go over quota with no penalties if the national milk deliveries 
are under. Both permanent and temporary transactions of quota have been decreasing during the period as well as the number of producers leasing quota $(\mathrm{Ru}-$ ral Payments Agency, 2002-2007; Milk Development Council, 2009). Movements of net regional purchases of wholesale quota have been reduced between 2002 and 2007. A transfer of wholesale quota from England to Wales, Scotland, and Northern Ireland has occurred (Rural Payments Agency, 2002-2007; Milk Development Council, 2009). With regard to the net lease of wholesale quota in England and Wales, the pattern is similar to that of purchasing wholesale quota. In net terms, England leases quota out whereas Wales leases quota in (Rural Payments Agency, 2002-2007; Milk Development Council, 2009).

We developed a theoretical background to incorporate the milk quota market into technical efficiency analysis, which allowed us to investigate whether different business structures regarding the use of quota market were correlated with inefficiency. To our knowledge, this is the first time the EU milk quota trade system has been incorporated into stochastic frontier analysis. Recently, Breustedt et al. (2011) incorporated a milk quota system, where milk quota was not easily adjusted in the short run, into data envelopment analysis to examine the effect of abolishment of the EU milk quota on the competitiveness of organic dairy farming in the Bavaria region of Germany. Hennessy et al. (2009) studied the inefficiencies associated with regionalized milk quota trade and found that the more freely quota is traded, the more efficient the outcome of the sector as a whole. Colman (2000) studied the economic efficiency of UK dairy farms under a milk marketing quota system and found that despite tradable quotas, a significant number of dairy farmers achieved a poor match between available quota and production.

This article is dedicated to examining the technical efficiency of milk-producing farms under the CAP milk quota system using stochastic frontier analysis (Aigner et al., 1977; Meeusen and van den Broeck, 1977), which has been used previously to study technical efficiency in dairy farms (Lawson et al., 2004; Iraizoz et al., 2005; Cabrera et al., 2010). We address the abolition of quota and the likely implications for the English and Welsh dairy sector. Both average and individual performance of dairy farms in England and Wales between 2000 and 2005 were evaluated using a sample of a stochastic multiple output distance function, the parameters of which were estimated carrying out a Bayesian approach.

\section{MATERIALS AND METHODS}

We developed a theoretical background using microeconomic theory to establish the role of a production quota system that allows quota transfer at the farm level into a stochastic frontier analysis. Therefore, developing the theoretical background serves to assign a role to both the annual allocation of quota and leasing quota in the analysis of production frontier. Milk producers in England and Wales have an annual milk quota that partially binds production during the period studied. It is partially bound because producers can lease in or lease out milk during the production year. Therefore, we included in the analysis the fact that production is partially constrained by the annual quota $Q$, leasing in quota qui, and leasing out quota quo (see equation [1]).

The case of milk production under a quota is interesting because the conventional objective for the farmer of maximizing profits is partially constrained by the availability of quota. It is not completely constrained because the farmer can buy or sell, and lease in or lease out, quota. Not accounting for such constraints may lead to wrongly attributing the effects of such constraint to the farmer being unsuccessful in optimizing production (Färe et al., 1994). The problem that the dairy farmer faces is to adjust variable inputs and outputs to maximize the following profit function $\pi$ subject to technological and supply restrictions:

$$
\begin{gathered}
\max _{x, q u i, q u o} \pi=\mathbf{p}^{\prime} \mathbf{y}+p_{q} q u o-\mathbf{w}^{\prime} \mathbf{x}-w_{q} q u i \\
\text { such that } f(\mathbf{x})=\mathbf{y} \text {, where } y_{1} \leq Q+q u i-q u o \\
Q=Q_{t}=Q_{t-1}+\text { quota bought }_{t}-\text { quota sold }_{t},
\end{gathered}
$$

where $\mathbf{y}=\left(y_{1}, \ldots, y_{M}\right)$ is a vector of outputs being $y_{1}$ milk output; quo, which is the quota leased out; $\mathbf{p}=\left(p_{1}, \ldots, p_{M}\right)$ is a vector of output prices; $p_{q}$ is the price of quota leased out; $\mathbf{x}=\left(x_{1}, \ldots, x_{K}\right)$ is a vector of inputs; $\mathbf{w}=\left(w_{1}, \ldots, w_{K}\right)$ is a vector of input prices; $w_{q}$ is the price of leased in quota; qui is the quota leased in; and $Q_{t}$ is the initial quota allocated in year $t$. The quota leased in and the quota leased out are treated as endogenous variables, as an input and an output respectively (i.e., they are optimized in this problem). The solution to the problem [1] represents both the optimal allocation of inputs and the optimal level of output. The regularity conditions require the profit function to be increasing in output, linear homogeneous in output and input prices, convex in output and input prices. The annual allocation of quota $Q$ is treated as given (i.e., exogenous), as a quantity that is fixed annually.

The profit maximizing output supplies, input demands can be obtained using the Lagrangian method. The Lagrangian function from [1] is

$$
L=\mathbf{p}^{\prime} f(\mathbf{x})+p_{q} q u o-\mathbf{w}^{\prime} \mathbf{x}-w_{q} q u i-\lambda(f(\mathbf{x})-Q-q u i+q u o) .
$$


The first-order conditions are

$$
\begin{gathered}
\frac{\partial L}{\partial x_{k}}=p_{k} \frac{\partial f(\mathbf{x})}{\partial x_{k}}-w_{k}-\lambda \frac{\partial f(\mathbf{x})}{\partial x_{k}}=0, \\
\frac{\partial L}{\partial q u i}=-w_{q}+\lambda=0 \Rightarrow \lambda=w_{q}, \\
\frac{\partial L}{\partial q u o}=p_{q}-\lambda=0 \Rightarrow \lambda=p_{q}, \\
\frac{\partial L}{\partial \lambda}=f(\mathbf{x})-Q-q u i+q u o=0 .
\end{gathered}
$$

From equations [4] and [5], we obtain equilibrium of the quota prices $\left(p_{q}=w_{q}\right)$. By solving this system, it is possible to obtain the optimal factor demand curves. For instance, assuming a translog production function, we would obtain $x_{k}=x_{k}^{*}\left(\mathbf{p}, \mathbf{w}, x_{l}, y_{m}, p_{q}, w_{q}, Q\right)$, $q u o=q u o^{*}\left(\mathbf{p}, \mathbf{w}, x_{l}, y_{m}, p_{q}, w_{q}, Q\right), \quad$ and $q u i=q u i^{*}\left(\mathbf{p}, \mathbf{w}, x_{l}, y_{m}, p_{q}, w_{q}, Q\right)$. The optimal factor demands are dependent on the prices of outputs, including the price of leasing out quota, prices of inputs including the price of leasing in quota, the inputs used including leased in quota, the outputs produced in including the leased out quota and the quota allocated for the year, $Q$. Therefore, demands of inputs adjust to the leasing of milk quota and to the allocation of quota for the year, $Q$. Substituting the input demands into the production function yields $y^{*}\left(p, w, x_{l}, y_{m}, p_{q}, w_{q}, Q\right)$. The maximum profit attainable by the farmer at those optimal factor and output prices is given by the indirect profit function $\pi^{*}\left(p, w, x_{l}, y_{m}, p_{q}, w_{q}, Q\right)$. Therefore, our model establishes that, for an efficiency analysis using production functions such as a translog partially constrained by the availability of quota in the way described here, the initial allocation of quota, the leased out quota, and the leased in quota may be incorporated to the production function in the same way as conventional inputs and outputs.

Optimizing behavior is the assumption on which conventional microeconomics is based. This means that producers optimize their production by not wasting resources and therefore operate near their production possibilities set. However, an array of motives may exist for which not all producers are successful in optimizing production. If this is the case, technical efficiency is not achieved and measuring the distance between the production frontier and actual production is a crucial policy interest. From a policy and managerial perspective, it is important to know the factors behind inefficiencies and how inefficient producers are on average as well as individually (Farrell, 1957; Färe et al., 1994). In particular, this article focuses on the correlation between milk quota trade and efficiency using 4 ways to describe milk quota trade. Theory suggests that the most-efficient farms buy or lease quota from lessefficient farms (Harvey, 1985; Burrell, 1989).

The analysis of technical efficiency presented here is based on distance functions. Distance functions are useful because they describe technology in a way that efficiency can be measured for multi-input and multioutput enterprises (Coelli et al., 2005) as in this case. An output distance function describes the degree to which a firm can expand its output given its input vector. The econometric approach to estimating such functions typically involves factoring out one of the outputs, in our case milk and other milk output, and estimating the resulting equation using conventional stochastic frontier estimation methods (see Appendix for further description of how to obtain an estimable regression model by normalizing one of the outputs).

\section{Estimation}

A translog form is specified for the distance function (see Appendix). The model obtained after normalizing by the milk and other milk output that needs to be estimated is

$$
y_{i, t}=\mathbf{x}_{i, t}^{\prime} \boldsymbol{\beta}+\varepsilon_{i, t}-z_{i} ; i=1, \ldots, N ; t=1, \ldots, T,
$$

where $y_{i, t}$ is an observation of the dependent variable of the ith farm at time $t$ (i.e., milk and other milk output), $x_{i, t}$ are the regressors or independent variables (i.e., other outputs, inputs, other inputs and interlinkages between them given by a translog function) in the model for the $i$ th farm at time $t, \boldsymbol{\beta}$ is vector of unknown parameters to be estimated $\varepsilon_{i, t}$ is the normal error for the $i$ th farm at time $t$, and $z_{i}$ is the inefficiency term of the $i$ th farm (i.e., time-invariant inefficiency).

If we stack all variables into matrices (using $\mid$ as a stack operator), we can write the regression model above as

$$
\mathbf{y}_{i}=\mathbf{X}_{i}^{\prime} \boldsymbol{\beta}+\boldsymbol{\varepsilon}_{i}-z_{i} \mathbf{1}_{\mathbf{T}},
$$

where $\quad \mathbf{y}_{i}=\left(y_{i, 1}|\ldots| y_{i, T}\right) ; \quad \mathbf{X}_{i}^{\prime}=\left(x_{i, 1}^{\prime}|\ldots| x_{i, T}^{\prime}\right)$; $\mathbf{1}_{\mathbf{T}}=(1|\ldots| 1) ;$ and $\boldsymbol{\varepsilon}_{i}=\left(\varepsilon_{i, 1}|\ldots| \varepsilon_{i, T}\right)$.

Averaging over $T$, we obtain

$$
\bar{y}_{i}=\overline{\mathbf{x}}_{i}^{\prime} \boldsymbol{\beta}-z_{i}+\bar{e}_{i},
$$

where

$\bar{y}_{i}=T^{-1} \sum_{t=1}^{T} y_{i, t} ; \overline{\mathbf{x}}_{i}=T^{-1} \sum_{t=1}^{T} x_{i, t} ; \bar{e}_{i}=T^{-1} \sum_{t=1}^{T} \varepsilon_{i, t}$, 
and in matrix terms

$$
\mathbf{y}=\mathbf{X} \boldsymbol{\beta}-\mathbf{z}+\mathbf{e}
$$

where $\quad \mathbf{y}=\left(y_{1}|\ldots| y_{N}\right) ; \quad \quad \mathbf{X}=\left(X_{1}^{\prime}|\ldots| X_{N}^{\prime}\right)$; $\mathbf{z}=\left(z_{1}|\ldots| z_{N}\right) ;$ and $\mathbf{e}=\left(\varepsilon_{1}|\ldots| \varepsilon_{N}\right)$.

Our choice of estimation methodology is Bayesian Markov chain Monte Carlo (MCMC; see Koop, 2003 for a detailed explanation). This method is easily implemented in the context of the frontier model used in this paper. As with the majority of current Bayesian applications, we limited ourselves to mainly reporting only the first 2 moments of the posterior distributions (the mean and standard deviation). However, the examination of the full posterior of each of the model parameters obtained using MCMC can often give the investigator further useful information. Computationally, MCMC methods do not impose a great burden, with the model being estimated in a matter of minutes. Bayesian methods are flexible, providing the optional use of prior information, and treat inequality restrictions in a way that classical estimation cannot. In this paper, we have been broadly "noninformative" and have chosen not to impose inequality conditions, other than those required for inefficiency to be nonnegative. Therefore, if classical methods (e.g., maximum likelihood) were used to estimate the models within this paper they would, most likely, yield similar results to the Bayesian ones produced herein. An advantage of the MCMC approach is that the distributions of the latent variables, such as the individual firm inefficiencies, are automatically mapped as part of the estimation process, rather than having to be estimated ex post, as in the classical case.

Under a Bayesian approach, the posterior inference is based on the conditional distributions of the parameters given the observables (Fernández et al., 2000), which can be obtained from the conditional likelihood function and the prior distributions. For a detailed description of how conditional distributions are obtained, see Appendix.

\section{Data}

The source of data used in this research is the Farm Business Survey, which was provided by the Agricultural and Market Economics Division within the Department for Environment, Food and Rural Affairs (Defra). It gives information at the farm level on a wide number of economic and physical aspects of a sample of farm businesses in England and Wales since 1984. We focused on the period from 2000 to 2005, which included a total of 215 dairy farms in England and
Wales for which information was available for the whole period analyzed (i.e., panel data). Efficiency is assumed to be time-invariant, which for a longer period would be a difficult assumption to maintain. The Farm Business Survey data included a large amount of information related to the farm enterprise such as milk output, leasing out quota, leasing in quota, utilized agricultural area (UAA), herd size, labor, machinery and general costs, and livestock costs (Table 1). Milk output is the quantity of milk produced per year, whereas leasing out quota and leasing in quota are the quantities leased per year by farms. Dealing with multi-input, multi-output farms can be complicated if the number of inputs and outputs is large. If this is the case, estimation problems may occur due to the loss of degrees of freedom. In addition, some of the inputs or outputs might have a zero value for some farms in particular years, which precludes the use of some common functional forms such as the translog. To overcome such difficulties, index numbers were used to aggregate the data into a smaller number of inputs and outputs. The farm outputs were aggregated into 3 categories: milk and other milk products, leasing out quota, and other output, which includes cereals, other crops, and livestock output. To aggregate the outputs into milk and other milk products, and other products, quantity Fisher index numbers were calculated. The Fisher index number is the geometric mean of the Laspeyres and Paasche indices. This index is preferred because it can handle zero quantities in the data set, which others, such the Tornqvist index, cannot. The use of the Fisher indices is recommended by Coelli et al. (2005) when zeros in the data need to be accommodated. To calculate the Fisher index, data on quantities and prices of the conventional outputs were used. Prices were previously deflated using agricultural price indices for the UK (Defra, 2009).

The inputs included in the analysis were UAA (ha); herd size (no. of cows); labor $(£)$; machinery and general farming costs $(£)$, which includes contract work, machinery rental, machinery and equipment valuation, machinery and equipment repairs, machinery, vehicle fuel and oil, electricity, heating fuel for all purposes, water for all purposes, insurance excluding labor and farm buildings, bank charges, professional fees, vehicle tax, and other general farming costs; and livestock costs $(£)$, which includes concentrate feeding stuff, coarse fodder, veterinary, and medicines.

The data were normalized so that each variable had a sample mean of 1 . This means that the monotonicity conditions can be expressed as $\alpha_{m} \geq 0$ and $\beta_{k} \leq 0$. It is worth noting that the sign of coefficient results have been changed and therefore the expected coefficients should be $\alpha_{m} \leq 0$ (i.e., negative sign for other outputs) and $\beta_{k} \geq 0$ (i.e., positive sign for inputs). This has been 
Table 1. Descriptive statistics of the variables used

\begin{tabular}{|c|c|c|c|c|}
\hline Variable & Minimum & Maximum & Mean & SD \\
\hline Milk (Fisher index) & 1 & 898 & 100 & 77 \\
\hline Leasing out quota (L) & 0 & 15,103 & 208 & 926 \\
\hline Other output (Fisher index) & 0 & 678 & 125 & 94 \\
\hline Utilized agricultural area (ha) & 16 & 883 & 118 & 109 \\
\hline Milk quota $(\mathrm{L})$ & 23,600 & $4,404,100$ & 713,416 & 515,840 \\
\hline Number of cows & 4 & 790 & 110 & 74 \\
\hline Leasing in quota $(\mathrm{L})$ & 0 & 19,000 & 512 & 1,389 \\
\hline Machinery and general costs $(£)$ & 4,531 & 195,274 & 40,484 & 30,772 \\
\hline Labor costs $(£)$ & 12,009 & 231,573 & 46,101 & 28,835 \\
\hline Livestock costs $(£ /$ cow $)$ & 84 & 1,880 & 511 & 208 \\
\hline
\end{tabular}

done to facilitate interpretation of the signs (e.g., positive sign for inputs, meaning an increase in inputs leads to an increase in milk production).

The use of a milk quota market may help to adjust inefficiencies derived from over- or underproduction capacities. We examined whether the way in which the milk quota market was used by farmers affected farm efficiency. Milk quota trade was specified in 3 alternative means that were analyzed separately using 3 alterations of the same model (M1, M2, and M3). These 3 variants aimed to examine (1) whether the level of participation in the quota market was correlated to efficiency. We may expect farmers participating in a relatively large scale in the quota market to be efficient farmers who are willing to expand their business by acquiring quota or those who are largely inefficient and need to dispose of quota. Relatively small participants in the market may be expected to be those that are efficient and do not decide or cannot expand due to financial constraints; (2) whether farmers who purchase or lease quota in are more efficient than those who sell or lease quota out. It is foreseen, based on theoretical grounds (Harvey, 1985; Burrell, 1989), that if some farmers are more efficient than others, farmers acquiring quota either by buying it or leasing it in would be more efficient than those reducing their allocation of milk production; (3) whether milk deliveries over the quota allocated indicate more efficient farms and deliveries under the quota indicate less efficient farms. Indeed, it is expected that farmers who deliver more milk than the amount allocated to them are taking advantage of the system and are more efficient than those who fall short in their allowed production levels, especially in years where national milk deliveries are under quota and no penalties are suffered by the farmer. Producers pay levy only when they exceed their own quota and the Member State exceeds the national quota.

To examine these aspects, several dummy variables were built. To examine (1), we first added the amount of quota bought or sold and the amount of quota leased in or out during the period. By taking the absolute value, we have a measure of the level of participation in the market. The first quartile of this variable represents small participants (i.e., <22,198 L traded), whereas the last quartile represents large participants (i.e., $>267,800 \mathrm{~L}$ traded). Three dummy variables were built based on quartiles of the measure of participating in the market. To examine (2), subtracting the amount of quota at the end of the period from the amount of quota at the beginning of the period taking into account the amount of quota leased in/out during the period gives the total quota change over the period. We classified farmers as "large buyers" (i.e., farmers who bought quota over the period and were above the median of the buyers of quota), "small buyers" (i.e., farmers who bought quota over the period and were below the median of buyers of quota), "small sellers" (i.e., famers that sold quota over the period and were below the median of sellers of quota), and "large sellers" (i.e., farmers that sold quota over the period and were above the median of sellers of quota). Finally, to examine (3), we first added the absolute quantities over/under quota per farm over the whole period and divided the result by the initial amount of quota in the year 2000. Quartiles of this variable were obtained, resulting in $25 \%$ of farmers having delivered below one-sixth of their initial allocation of quota, and another $25 \%$ of farmers having delivered over three-fourths of their initial allocation of quota. Three dummies were obtained labeled as "farms relatively under quota" (i.e., first quartile), "farms relatively close to quota" (i.e., second and third quartile), and "farms relatively over quota" (i.e., fourth quartile).

In addition to examining whether (1) the level of participation in the milk market by farmers, (2) the role of the farmer in the market (i.e., buyer or seller), and (3) the milk deliveries being relatively under or over quota affect farm efficiency, other variables were used to explain inefficiencies (Table 2). A dummy variable accounting for set-aside payment was created by dividing the total set-aside payments to the farm by the total agricultural area. This effectively measures the percentage of the total agricultural area allocated 
to produce arable crops. By obtaining the median of this measure, a dummy variable was created, which effectively differentiated between those farms that are less specialized in milk production (i.e., those above the median of the measure) and more specialized in milk production (those below the median of the measure). Environmental payments include agri-environmental payments and other environmental schemes. A dummy variable for environmental payments was created to examine the correlation between such payments and farm efficiency. This was created by dividing the total environmental payments received by the farm by the total agricultural area and giving a value of 1 for values above the median and zero for values below the median. Financial pressure has been cited previously in the literature as a possible determinant of efficiency and found to be both negatively related to efficiency (Morrison Paul et al., 2000; Iraizoz et al., 2005; Hadley, 2006) and positively related (Jensen, 1986; Giannakas et al., 2001; Davidova and Latruffe, 2007; Barnes, 2008). The negative relationship between financial pressure and technical efficiency is based on agency theory and credit evaluation approach (Davidova and Latruffe, 2007). The agency theory states that highly indebted farmers might incur higher costs and be less efficient (Jensen and Meckling, 1976), whereas the credit evaluation approach is based on the banks preference to lend money to low risk borrowers (i.e., the most technically efficient; Davidova and Latruffe, 2007). This positive correlation between financial pressure and efficiency was also found by Barnes (2008), who suggested that it may indicate increasing investment in more efficient capital assets. Hadley (2006) uses a ratio of rental equivalent (i.e., the sum of interest and rent paid, charges that must be paid when they fall due and nonpayment of which could result in loss of tenure or foreclosure of loans) to gross margin; Morrison Paul et al. (2000) use a debt:equity ratio to account for financial pressure; and Iraizoz et al. (2005) use a ratio of paid rents and interests to gross margin. On the other hand, a negative relationship between financial pressure and technical efficiency is based on free cash flow theory, which suggests that farmers who are indebted need to meet their payment obligations and, therefore, are motivated to improve their efficiency. In this research, a ratio between external liabilities and total assets was calculated and used to account for financial pressure. The mean of the financial pressure ratio from the sample was 0.10 , whereas the median was 0.05 . A dummy variable was created, allocating a value of 1 for those ratio values larger than 0.10. Farmer's age was taken into account by creating a dummy variable in which the median age of the sample was the value used to distinguish farmers by age.
A dummy accounting for farms in a less favorable area (LFA) was included in the analysis to examine whether farms located in LFA were less efficient than farms located in a non-LFA. Hadley (2006) found a small negative effect on efficiency of dairy farms located in LFA. Barnes (2008) also found similar results for dairy farms in Scotland. In addition, dummy variables for Government Office Regions in England and Wales were introduced to account for any differences in efficiency between regions.

\section{RESULTS AND DISCUSSION}

Three alternative models (M1 to M3) were used to examine farm efficiency of dairy farms in England and Wales, with the only difference between them being the way the milk quota trade was specified. All models produced similar results regarding estimated parameters for the production function. Results for the parameters associated with inputs and outputs of the production function are shown in Table 3. Highest posterior densities at the $90 \%$ level are also reported. These are coverage posterior regions, which are calculated as the 5 th and 95th percentiles of the posterior distribution of the coefficients. These coverage posterior regions are conventional statistics in Bayesian applications with high posterior densities (Holloway et al., 2002). All signs are as expected with the exception of the coefficient for leasing quota in, which is negative but the $90 \%$ coverage posterior region shows that no clear evidence supports the belief of this coefficient being negative. The number of cows and the amount of milk quota allocated at the beginning of the year were the 2 most important inputs in terms of milk production, whereas the production of other outputs by the farm reduced the production of milk, holding everything else constant.

Figure 1 shows the conditional posterior probability density function for mean efficiency across the sample of dairy farms for the 3 models. The technical efficiency of the sample of the dairy farms ranged from 0.32 to 0.98 with median 0.89 and mean 0.85 for M1; from 0.33 to 0.98 with median 0.90 and mean 0.85 for M2; and from 0.34 to 0.98 with median 0.90 and mean 0.85 for M3. Despite milk quota being tradable, several farms still score low efficiency levels. Table 4 shows the results for the estimates of the parameters $\varphi_{j}$ associated with the explanatory variables for inefficiency.

The 3 specifications used to account for the level and type of participation in the quota market (models M1 to M3) provided insight on the linkages between the use of quota market by farmers and technical efficiency. Thus, farmers who acquire quota by buying it or leasing it in tend to be more efficient than those who sell or lease out quota. This result is in concordance with the- 
Table 2. Explanatory variables for inefficiency

\begin{tabular}{ll}
\hline Variable & Definition \\
\hline Set-aside payment & 1 if the farm above the median of set-aside payments/total agricultural area; 0 otherwise \\
Environmental payments & 1 if the farm above the median of total environmental payments/total agricultural area; 0 otherwise \\
Financial pressure & 1 if external liabilities/total assets $>0.10$ and 0 if external liabilities/total assets $<0.10$ \\
Average quota market participants & 1 if the quota traded is between 22,198 (first quartile) and 267,800 (fourth quartile) liters; 0 otherwise \\
Large quota market participants & 1 if the quota traded is greater than $267,800 \mathrm{~L}$ (fourth quartile); 0 otherwise \\
Small buyers & 1 if farmer bought below $122,522 \mathrm{~L}$ of quota over the period studied; 0 otherwise \\
Small sellers & 1 if farmer sold below $23,600 \mathrm{~L}$ of quota over the period studied; 0 otherwise \\
Large sellers & 1 if farmer sold above 23,600 L of quota over the period studied; 0 otherwise \\
Farms relatively close to quota & 1 if the absolute over/under quota quantity over the period divided by the initial \\
& quota in 2000 belongs to the second and third quartile; 0 otherwise \\
Farms relatively under quota & 1 if the absolute over/under quota quantity over the period divided by the \\
& initial quota in 2000 belongs to the first quartile; 0 otherwise \\
Farmer's age & 1 if the farmer's age is $>52 ; 0$ otherwise \\
Less favorable area (LFA) & 1 if the farm is located in a LFA; 0 otherwise \\
Northeast (NE) & 1 if the farm is located in NE region; 0 otherwise \\
Yorkshire and Humber (Y\&H) & 1 if the farm is located in Y\&H region; 0 otherwise \\
Northwest (NW) & 1 if the farm is located in NW region; 0 otherwise \\
East Midlands (EM) & 1 if the farm is located in EM region; 0 otherwise \\
East England (EE) & 1 if the farm is located in EE region; 0 otherwise \\
Southeast (SE) & 1 if the farm is located in SE region; 0 otherwise \\
Southwest (SW) & 1 if the farm is located in SW region; 0 otherwise \\
Wales (WA) & 1 if the farm is located in WA region; 0 otherwise \\
\hline
\end{tabular}

ory, which states that if a market for quota exists, the most-efficient farmers will buy from the least-efficient farmers. We found that, in all models, the way in which the quota market was used by farmers was associated with (in)efficiency. Thus, the level of participation in the quota market by farmers was found to be correlated with efficiency. Results from model M1 showed that farms that participated in a relatively large scale in the quota market were more efficient than those that participated relatively less. We expected large participants to be efficient farmers who are willing to expand their business. Indeed, $94 \%$ of large participants in the market were net buyers of quota over the whole period. This result is consistent with results obtained from model M2, where large net quota sellers were found to be less efficient than large net quota buyers. Milk deliveries by the farm were found to be correlated with farm (in)efficiency. Thus, farms that tend to fall under allocated quota are less efficient than farms whose milk quota delivery is over the farm allocated quota.

Seventy-six farms in the sample received environmental payments. Results suggest that those farmers who receive relatively high environmental payments (i.e., they conduct complex environmental management) are less efficient than those who receive relatively small payments for managing the environment or receive no payment at all. Another interpretation of the results is that more-efficient farms do not take on relatively high payments for managing the environment. However, this does not mean that when less-efficient farms do take on environmental payments they do not increase efficiency. Payments to farmers have previously been found to have a negative effect on technical efficiency (Zhu and Lansink, 2010). In contrast to environmental

Table 3. Slope parameters for models (M) 1, 2, and 3 (dependent variable $=$ milk output $)^{1}$

\begin{tabular}{|c|c|c|c|c|c|c|}
\hline \multirow[b]{2}{*}{ Item } & \multicolumn{2}{|c|}{ M1 } & \multicolumn{2}{|c|}{ M2 } & \multicolumn{2}{|c|}{ M3 } \\
\hline & Coefficient & $90 \%$ posterior & Coefficient & $90 \%$ posterior & Coefficient & $90 \%$ posterior \\
\hline Intercept & -0.01 & $(-0.08,0.06)$ & -0.01 & $(-0.07,0.06)$ & -0.01 & $(-0.08,0.06)$ \\
\hline Leasing quota out & -0.12 & $(-0.18,-0.06)$ & -0.11 & $(-0.17,-0.05)$ & -0.11 & $(-0.17,-0.05)$ \\
\hline Other output & -0.29 & $(-0.33,-0.25)$ & -0.29 & $(-0.33,-0.25)$ & -0.29 & $(-0.33,-0.25)$ \\
\hline Utilized agricultural area & 0.06 & $(0.01,0.11)$ & 0.06 & $(0.01,0.11)$ & 0.05 & $(0.00,0.10)$ \\
\hline Milk quota & 0.35 & $(0.25,0.45)$ & 0.36 & $(0.26,0.46)$ & 0.38 & $(0.27,0.48)$ \\
\hline Number of cows & 0.42 & $(0.32,0.53)$ & 0.43 & $(0.32,0.54)$ & 0.43 & $(0.32,0.54)$ \\
\hline Leasing quota in & -0.02 & $(-0.05,0.02)$ & -0.02 & $(-0.05,0.02)$ & -0.01 & $(-0.05,0.02)$ \\
\hline Machinery and general costs & 0.10 & $(0.03,0.17)$ & 0.10 & $(0.03,0.17)$ & 0.10 & $(0.03,0.17)$ \\
\hline Labor costs & 0.04 & $(-0.02,0.10)$ & 0.03 & $(-0.03,0.10)$ & 0.04 & $(-0.03,0.10)$ \\
\hline Livestock costs (per cow) & 0.17 & $(0.11,0.23)$ & 0.17 & $(0.11,0.24)$ & 0.18 & $(0.12,0.24)$ \\
\hline
\end{tabular}

${ }^{1}$ Estimates based on Gibbs sample size of 25,000. Numbers in parentheses indicate $90 \%$ coverage region intervals. 


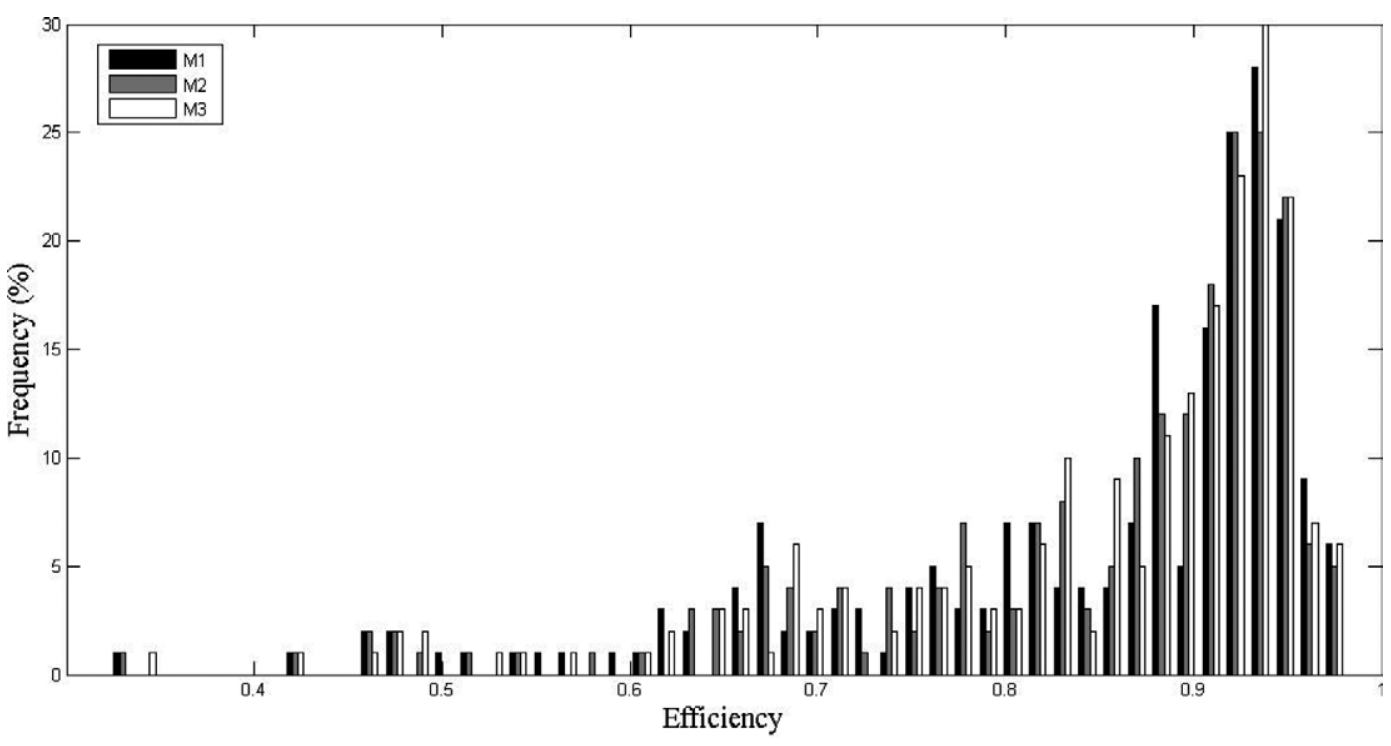

Figure 1. Conditional posterior distributions for mean efficiency across the sample. M1, M2, and M3 = models 1,2 , and 3 .

payments, set-aside payments are negatively correlated with inefficiency. Sixty-seven farms in the sample received set-aside payments during the period studied. Set-aside payments are calculated per hectare of UAA, which is effectively a measure of the percentage of arable land. Therefore, those milk producer farms that also specialize in arable production have lower levels of inefficiency than milk producer farms where arable production is less important. This result may indicate that linkages between arable crop production and milk production such as the use of arable crops for feed- ing are key to be more efficient. Model results showed that financial pressure was positively correlated with inefficiency although not statistically relevant based on the $90 \%$ posterior region. An interpretation for this is that those farmers with higher financial pressure tend to be less efficient than those who are not under financial pressure. This finding is in concordance with results obtained in previous studies on the influence of debt ratios on technical efficiency (Morrison Paul et al., 2000; Iraizoz et al., 2005; Hadley, 2006). No effect on efficiency was found for farmer's age. The location

Table 4. Explanatory variables of inefficiency: coefficient estimates and $90 \%$ coverage posterior regions $^{1}$

\begin{tabular}{|c|c|c|c|c|c|c|}
\hline \multirow[b]{2}{*}{ Item } & \multicolumn{2}{|c|}{ M1 } & \multicolumn{2}{|c|}{ M2 } & \multicolumn{2}{|c|}{ M3 } \\
\hline & Coefficient & $90 \%$ posterior & Coefficient & $90 \%$ posterior & Coefficient & $90 \%$ posterior \\
\hline Intercept & 0.19 & $(0.11,0.33)$ & 0.15 & $(0.08,0.25)$ & 0.12 & $(0.07,0.21)$ \\
\hline Average quota market participants & -0.17 & $(-0.49,0.16)$ & - & - & - & - \\
\hline Large quota market participants & -0.73 & $(-1.15,-0.32)$ & - & - & - & - \\
\hline Small buyers & - & - & 0.18 & $(-0.14,0.50)$ & - & - \\
\hline Small sellers & - & - & 0.30 & $(-0.17,0.78)$ & - & - \\
\hline Large sellers & - & - & 0.59 & $(0.01,1.12)$ & - & - \\
\hline Farms relatively close to quota & - & - & - & - & 0.21 & $(-0.12,0.56)$ \\
\hline Farms relatively under quota & - & - & - & - & 0.55 & $(0.17,0.94)$ \\
\hline Environmental payment & 0.45 & $(0.11,0.80)$ & 0.43 & $(0.08,0.78)$ & 0.47 & $(0.12,0.83)$ \\
\hline Set-aside payment & -0.63 & $(-1.12,-0.14)$ & -0.65 & $(-1.15,-0.16)$ & -0.72 & $(-1.25,-0.22)$ \\
\hline Financial pressure & 0.21 & $(-0.07,0.50)$ & 0.08 & $(-0.23,0.39)$ & 0.13 & $(-0.16,0.43)$ \\
\hline Age & -0.05 & $(-0.33,0.23)$ & -0.10 & $(-0.41,0.18)$ & -0.01 & $(-0.30,0.29)$ \\
\hline Less favorable area & 0.08 & $(-0.26,0.43)$ & 0.01 & $(-0.33,0.36)$ & 0.04 & $(-0.30,0.40)$ \\
\hline Northeast & 0.21 & $(-0.82,1.49)$ & 0.22 & $(-0.80,1.49)$ & 0.28 & $(-0.76,1.58)$ \\
\hline Yorkshire and Humber & 0.11 & $(-0.60,0.85)$ & 0.01 & $(-0.72,0.76)$ & 0.04 & $(-0.74,0.82)$ \\
\hline Northwest & 0.56 & $(0.02,1.13)$ & 0.54 & $(-0.02,1.14)$ & 0.52 & $(-0.05,1.08)$ \\
\hline East Midlands & -0.24 & $(-0.88,0.44)$ & -0.25 & $(-0.91,0.44)$ & -0.17 & $(-0.83,0.50)$ \\
\hline East England & 0.87 & $(0.07,1.76)$ & 0.88 & $(0.07,1.77)$ & 1.14 & $(0.30,2.06)$ \\
\hline Southeast & 0.05 & $(-0.61,0.74)$ & 0.08 & $(-0.58,0.79)$ & 0.09 & $(-0.58,0.79)$ \\
\hline Southwest & 0.22 & $(-0.29,0.74)$ & 0.12 & $(-0.42,0.67)$ & 0.12 & $(-0.41,0.64)$ \\
\hline Wales & -0.17 & $(-0.69,0.37)$ & -0.18 & $(-0.73,0.38)$ & -0.28 & $(-0.82,0.27)$ \\
\hline
\end{tabular}

${ }^{1}$ Estimates based on Gibbs sample size of 25,000 . Numbers in parentheses indicate $90 \%$ coverage region intervals. $\mathrm{M}=$ model. 
of the farm on LFA was found not to be associated with efficiency. With regard to regional differences, only farms in east England were found to less efficient than farms located in the benchmark region (West Midlands). Farms located in the northwest also tended to be less efficient than in the West Midlands, although this is not as highly supported by the coverage region as for the east England case. The rest of the regions did not show any difference in efficiency levels between them and the West Midlands region.

The abolition of the milk quota in 2015 will be a remarkable change in CAP. This change in policy will lead to a more competitive market for milk, which may force the least-efficient farms in Europe to leave milk production. The fact that adjustments to their production capabilities have been already carried out by English and Welsh farmers, through the use of a tradable milk quota system since the 1980s, means that they may be in a better position than farmers in France, Ireland, and Germany, where more restrictive quota systems are in place (i.e. the ring-fenced quota trade that restricts quota trade between different areas within the country). Any restriction in the tradability of quota such as the ring-fenced quota trade would have hampered the chances to restructure business by stopping the transfers of wholesale quota among UK regions as it happened.

Despite most of the dairy industry having been restructured, it is expected that a relatively small percentage of milk producers in England and Wales will keep expanding or reducing their production between now and even after the abolition of quota in 2015, although such changes should be marginal by then. Based on our results, production will be increased by efficient farmers, whereas the least efficient farmers may need policy support to face competition. In addition, we found that efficient farmers took advantage of the quota system by over delivering quota. Likely, farmers were confident they would not be penalized (i.e., the national milk deliveries would be under quota) because the trend of national milk deliveries was under quota in 5 out of 6 yr studied.

Overall, we foresee that the sector will continue to reduce the number of cows and holdings especially in areas such as the east England and perhaps northeast regions, at least before the abolition of quota. Complementing milk production with arable crops and taking advantage of their linkages is of critical importance to become more efficient. Therefore, encouraging or favoring diversification may lead to efficiency improvements, whereas care should be taken when putting in place environmental schemes with environmental payments because farmers may reduce efficiency.

\section{CONCLUSIONS}

Our results showed that being efficient was linked to acquiring quota through a tradable milk quota system. The level of participation in the quota market was correlated with efficiency. In particular, farmers who purchased or leased quota were found to be more efficient than those who sold or leased quota out. Also, those farms that tended to go over allocated quota were more efficient than farms whose milk quota delivery was below the farm allocated quota. Finally, farmers who received relatively high payments for conducting complex environmental management were less efficient than those who received relatively small payments or no payment at all.

\section{ACKNOWLEDGMENTS}

We thank Alan Swinbank (University of Reading, UK), 2 anonymous referees, and the section editor for their advice, suggestions and useful comments. We also thank the Economic and Social Research Council (ESRC) and the UK Department for Environment, Food and Rural Affairs (Defra) for funding this research.

\section{REFERENCES}

Aigner, D., C. A. K. Lovell, and P. Schmidt. 1977. Formulation and estimation of stochastic frontier production function models. J. Econom. 6:21-37.

Barnes, A. 2008. Technical efficiency estimates of Scottish Agriculture: A note. J. Agric. Econ. 59:370-376.

Breustedt, G., U. Latacz-Lohmann, and T. Tiedemann. 2011. Organic or conventional? Optimal dairy farming technology under the EU milk quota system and organic subsidies. Food Policy 36:223-229.

Brümmer, B., T. Glauben, and W. Lu. 2006. Policy reform and productivity change in Chinese agriculture: A distance function approach. J. Dev. Econ. 81:61-79.

Brümmer, B., T. Glauben, and G. Thijssen. 2002. Decomposition of productivity growth using distance functions: The case of dairy farms in three European countries. Am. J. Agric. Econ. 84:628644.

Burrell, A. M. 1989. The Microeconomics of Quota Transfer. CAB International, Wallingford, UK.

Cabrera, V. E., D. Solís, and J. del Corral. 2010. Determinants of technical efficiency among dairy farms in Wisconsin. J. Dairy Sci. 93:387-393.

Coelli, T. J., and S. Perelman. 1999. A comparison of parametric and non-parametric distance functions: With application to European railways. Eur. J. Oper. Res. 117:326-339.

Coelli, T. J., and S. Perelman. 2000. Technical efficiency of European railways: A distance function approach. Appl. Econ. 32:19671976.

Coelli, T. J., D. S. Prasada Rao, C. J. O’Donnell, and G. E. Battese. 2005. An introduction to efficiency and productivity analysis. 2nd Ed. Springer Science + Business Media,Inc., New York, NY.

Colman, D. 2000. Inefficiencies in the UK milk quota system. Food Policy 25:14-16.

Davidova, S., and L. Latruffe. 2007. Relationships between technical efficiency and financial management for Czech Republic farms. J. Agric. Econ. 58:127-141. 
Dawson, P. J. 1991. The simple analytics of agricultural production quotas. Oxford Agrar. Stud. 19:127-141.

Defra. 2009. API: Index of the purchase prices of the means of agricultural production. Annual data $(2000+100)$. Accessed Oct. 31, 2011. http://www.defra.gov.uk/statistics/files/defra-stats-foodfarm-farmgate-api-monthly2000.xls.

Defra. 2011. UK cattle, pigs, sheep and poultry numbers: 1866-present. Accessed Oct. 31, 2011. http://archive.defra.gov.uk/evidence/ statistics/foodfarm/landuselivestock/junesurvey/documents/ Livestock-1866onwards.xls.

Färe, R., S. Grosskopf, and C. A. Lovell. 1994. Production Frontiers. Cambridge University Press, Cambridge, UK.

Farrell, M. J. 1957. The measurement of productive efficiency. J. R. Stat. Soc. Ser. A-G 120:253-290.

Fernández, C., G. Koop, and M. F. J. Steel. 2000. A Bayesian analysis of multiple-output production frontiers. J. Econom. 98:47-79.

Fernández, C., J. Osiewalski, and M. F. J. Steel. 1997. On the use of panel data in stochastic frontier with improper priors . J. Econom. 79:169-193.

Giannakas, K., R. Schoney, and V. Tzouvelekas. 2001. Technical efficiency, technological change and output growth of wheat farms in Saskatchewan. Can. J. Agric. Econ. 49:135-152.

Hadley, D. 2006. Patterns in technical efficiency and technical change at the farm-level in England and Wales, 1982-2002. J. Agric. Econ. 57:81-100.

Harvey, D. 1985. Milk quotas: Freedom or serfdom? Centre for Agricultural Strategy, Reading, UK.

Hennessy, T., S. Shrestha, L. Shalloo, and M. Wallace. 2009. The inefficiencies of regionalised milk quota trade. J. Agric. Econ. 60:334-347.

Holloway, G., B. Shankar, and S. Rahman. 2002. Bayesian spatial probit estimation: A primer and an application HYV rive adoption. Agric. Econ. 27:383-402.

Iraizoz, B., I. Bardaji, and M. Rapun. 2005. The Spanish beef sector in the 1990s: Impact of the BSE crisis on efficiency and profitability. Appl. Econ. 37:473-484.

Jensen, M. C. 1986. Agency costs of free cash flow, corporate finance and takeovers. Am. Econ. Rev. 76:323-329.
Jensen, M. C., and W. Meckling. 1976. Theory of the firm: Managerial behaviour, agency costs and ownership structure. J. Financ. Econ. 3:305-360.

Koop, G. 2003. Bayesian Econometrics. John Wiley \& Sons Inc, Chichester, UK.

Koop, G., J. Osiewalski, and M. F. J. Steel. 1997. Bayesian efficiency analysis through individual effects: Hospital cost frontiers. J. Econom. 76:77-105.

Lawson, L. G., J. Bruun, T. Coelli, J. F. Agger, and M. Lund. 2004. Relationships of efficiency to reproductive disorders in Danish milk production: a stochastic frontier analysis. J. Dairy Sci. $87: 212-224$

Lovell, C. A. K., S. Richardson, P. Travers, and L. L. Wood. 1994 Resources and functionings: A new view of inequality in Australia. Springer-Verlag Press, Berlin, Germany.

Meeusen, W., and J. van den Broeck. 1977. Efficiency estimation from Cobb-Douglass production functions with composed error. Int Econ. Rev. 18:435-444.

Milk Development Council. 2009. Accessed Nov. 10, 2009. http:// www.dairyco.net/datum/dairy-processing-trade/eu-marketsupport/quota.aspx

Morrison Paul, C. J., W. E. Johnston, and G. A. G. Frengley. 2000. Efficiency in New Zealand sheep and beef farming: The impacts of regulatory reform. Rev. Econ. Stat. 82:325-337.

O'Donnell, C. J., and T. J. Coelli. 2005. A Bayesian approach to imposing curvature on distance functions. J. Econom. 127:493-523.

Orea, L. 2002. Parametric decomposition of a generalized Malmquist productivity index. J. Prod. Anal. 18:5-22.

Rural Payments Agency. 2002-2007. Milk quotas. Statistics tables Accessed Oct. 31, 2011. http://rpa.defra.gov.uk/rpa/index.nsf/UI Menu/4A334E8354FFBC6680256F72003D5985?Opendocument.

van den Broeck, J., G. Koop, J. Osiewalski, and M. F. J. Steel. 1994 Stochastic frontier models: A Bayesian perspective. J. Econom. 61:273-303.

Van Kooten, G. C., and J. Spriggs. 1984. A comparative static analysis of the welfare impacts of supply-restricting marketing boards. Can. J. Agric. Econ. 32:221-230.

Zhu, X., and A. O. Lansink. 2010. Impact of CAP subsidies on technical efficiency of crop farms in Germany, the Netherlands and Spain. J. Agric. Econ. 61:545-564. 


\section{APPENDIX}

To define a distance output function, we need to start from a producible output set, which is the set of all outputs that can be feasibly produced using the set of all inputs. The output set for production technology is defined as

$$
P(\mathbf{x}, Q)=\left\{y \in R_{+}^{M}: \mathbf{x} \text { can produce } \mathbf{y} \text { given } y_{1}=Q+q u i-q u o\right\}=\{\mathbf{y}:(x, y) \in T\},
$$

where $\mathbf{y}$ refers to all outputs of the farm including milk $\left(y_{1}\right)$, the leasing out of quota quo and other outputs (i.e., other crops and livestock), $\mathbf{x}$ refers to all inputs used in the farm including the leasing in quota qui and the annual allocation of quota $Q$ (where $Q=Q_{t}=Q_{t-1}+$ quota bought $_{t}-$ quota sold $_{t}$ ), and $R$ represents the set of real numbers.

The output distance function is defined on the output set $P(x, Q)$ as

$$
D_{O}(\mathbf{x}, \mathbf{y}, Q)=\min \left\{\theta:\left(\frac{\mathbf{y}}{\theta}\right) \in P(\mathbf{x}, Q)\right\} \text { for all } \mathbf{x} \in R_{+}^{K},
$$

which means that the initial allocation of quota $Q$, the leasing in qui and leasing out quota quo are treated in the same way as conventional inputs and outputs.

Assuming a translog functional form for the parametric distance function with $M$ outputs and $K$ inputs provides several attractive properties including flexibility, easy to derive, and permit the imposition of homogeneity, which makes it the preferred functional form for a distance function used in the literature (Lovell et al., 1994; Coelli and Perelman, 1999; Brümmer et al., 2002, 2006). By using linear homogeneity of the output distance function in outputs can be transformed into an estimable regression model by normalizing the function by one of the outputs (Lovell et al., 1994; Coelli and Perelman, 1999, 2000; Brümmer et al., 2002, 2006; Orea, 2002; O'Donnell and Coelli, 2005). From Euler's theorem, homogeneity of degree one in output implies

$$
\sum_{m=1}^{M} \alpha_{m}+\sum_{m=1}^{M} \sum_{n=1}^{M} \alpha_{m n} \ln \mathbf{y}_{n i}+\sum_{m=1}^{M} \sum_{k=1}^{K} \delta_{k m} \ln \mathbf{x}_{k i}=1
$$

which will be satisfied if $\sum_{m=1}^{M} \alpha_{m}=1, \sum_{m=1}^{M} \alpha_{m n}=0$ for all $n$, and $\sum_{m=1}^{M} \delta_{k m}=0$ for all $k$. Substituting these constraints is equivalent to normalizing by one of the outputs, which leads to the following expressions:

$$
\begin{gathered}
\ln D_{O}\left(\frac{y_{i}}{y_{2 i}}\right)=\ln D_{O} \frac{1}{y_{2 i}}\left(y_{i}, x_{i}\right), \\
-\ln y_{2 i}=\alpha_{0}+\sum_{m=1}^{M} \alpha_{1} \ln \frac{y_{m i}}{y_{2 i}}+\frac{1}{2} \sum_{m=1}^{M} \sum_{n=1}^{M} \alpha_{m n} \ln \frac{y_{m i}}{y_{2 i}} \ln \frac{y_{n i}}{y_{2 i}} \\
+\sum_{k=1}^{K} \beta_{k} \ln x_{k i}+\frac{1}{2} \sum_{k=1}^{K} \sum_{l=1}^{K} \beta_{k l} \ln x_{k l} \ln x_{l i}+\sum_{k=1}^{K} \sum_{m=1}^{M} \delta_{k m} \ln x_{k i} \ln \frac{y_{m i}}{y_{2 i}}+\varepsilon_{i}-z_{i},
\end{gathered}
$$

where $\varepsilon_{i}$ is a symmetric random error term that accounts for statistical noise and $z_{i}$ is a nonnegative random variable associated with technical inefficiency.

Monotonicity constraints involve constraints on functions of the partial derivatives of the distance function. As pointed out by O'Donnell and Coelli (2005), the elasticities of distance with respect to inputs and outputs are important logarithmic derivatives.

$$
\begin{aligned}
& \frac{\partial \ln D_{O}}{\partial \ln x_{k}}=\beta_{k}+\sum_{l=1}^{K} \beta_{k l} \ln x_{l i}+\sum_{m=1}^{M} \delta_{k m} \ln \frac{y_{m i}}{y_{2 i}}, \\
& \frac{\partial \ln D_{O}}{\partial \ln y_{m}}=\alpha_{m}+\sum_{n=1}^{M} \alpha_{m n} \ln \frac{y_{n i}}{y_{2 i}}+\sum_{k=1}^{K} \delta_{k m} \ln x_{k i} .
\end{aligned}
$$


For $D_{O}$ to be nonincreasing in $x, \frac{\partial \ln D_{O}}{\partial \ln x_{k}} \leq 0$, whereas for $D_{O}$ to be nondecreasing in $y, \frac{\partial \ln D_{O}}{\partial \ln y_{m}} \geq 0$.

\section{The Conditional Likelihood Function}

The assumption about the errors defines the likelihood function. In this case a normal distribution is assumed with mean $0_{T}$ and covariance matrix $h^{-1} \mathbf{I}_{\mathbf{T}} ; x_{i}$ are fixed nonstochastic variables; $\varepsilon_{i}$ and $\varepsilon_{j}$ are independent of one another for $i \neq j$ or, in other words, the errors are independent over all individuals and periods; $z_{i}$ and $\varepsilon_{j}$ are independent of one another for all $i$ and $j$. Equation [A8] represents the conditional likelihood function, which is proportional to a normal distribution:

$$
p(\mathbf{y} \mid \boldsymbol{\beta}, h, \mathbf{z}) \propto h^{\frac{T}{2}} \exp \left[-\frac{h}{2}\left(\mathbf{y}_{i}-\mathbf{x}_{i} \boldsymbol{\beta}+z_{i} \mathbf{l}_{\mathbf{T}}\right)^{\prime}\left(y_{i}-x_{i} \boldsymbol{\beta}+z_{i} \mathbf{l}_{\mathbf{T}}\right)\right],
$$

where $\mathbf{z}=\left(z_{1}, \ldots, z_{N}\right)^{\prime}$. Rearranging $\tilde{\mathbf{y}}_{i}=\left[\mathbf{y}_{i}+\mathbf{z}_{i} \mathbf{l}_{\mathbf{T}}\right]$, the following expression is obtained:

$$
p(\mathbf{y} \mid \boldsymbol{\beta}, h, \mathbf{z}) \propto h^{\frac{T}{2}} \exp \left[-\frac{h}{2}\left(\tilde{\mathbf{y}}_{i}-\mathbf{x}_{i} \boldsymbol{\beta}\right)^{\prime}\left(\tilde{\mathbf{y}}_{i}-\mathbf{x}_{i} \boldsymbol{\beta}\right)\right] .
$$

\section{The Priors}

The likelihood function must be complemented with a prior distribution on the parameters $(\beta, h, z)$ to carry out Bayesian inference. An independent normal-gamma prior is used for the coefficients in the production frontier and the error precision (see Koop, 2003 for a more detailed explanation on these priors).

The distribution of the inefficiency vector is determined by the distribution of $z$. The prior for $z$ is hierarchical, as in Fernández et al. (2000) and Koop et al. (1997) in the sense that an $r$-dimensional parameter vector $\varphi=\left(\varphi_{1}, \ldots, \varphi_{r}\right)$ is added, where each of the elements of the parameter vector $\varphi$ measures the effect of the inefficiency explanatory variables $w_{i j}$ into the inefficiency distribution. Given $\varphi, z$ has a probability density function given by

$$
p\left(z_{i} \mid \mu_{z}^{-1}(\boldsymbol{\varphi})\right)=\frac{z_{i}^{\alpha-1}}{\mu(\boldsymbol{\varphi})^{a} \Gamma(\alpha)} \exp \left(-\mu_{z}^{-1}(\boldsymbol{\varphi}) z_{i}\right),
$$

where $\Gamma(\cdot)$ indicates the Gamma function and $f_{G}\left(z_{i} \mid \alpha, \mu_{z}^{-1}(\varphi)\right)$ is the gamma density with parameters $\alpha$ and $\mu_{z}^{-1}(\varphi)$, mean $\mu_{z}(\varphi)$, and variance $\mu_{z}^{2}(\varphi)$. This prior is commonly used in the literature (van den Broeck et al., 1994; Koop et al., 1995; Fernandez et al., 1997). Assuming $\alpha=1$, the inefficiency distribution is exponential and the inefficiency prior becomes

$$
p\left(z_{i} \mid \mu_{z}^{-1}(\varphi)\right) \propto \exp \left(-\mu_{z}^{-1}(\varphi) z_{i}\right)
$$

As in Fernández et al. (1997), we take $\mu_{z}^{-1}(\varphi)$ to depend on $\varphi$ in the following way

$$
\mu_{z}^{-1}(\varphi)=\prod_{j=1}^{r} \varphi_{j}^{w_{i j}}
$$

where $w_{i j}$ are dummy variables and $w_{i 1}=1$. The prior for each of the elements of the vector $\varphi$ are taken to be independent and follow a gamma density with hyperparameters $e_{j}$ and $g_{j}$, which are associated with prior information about the location of the efficiency distribution. The values for the hyperparameters are $e_{1}=1$ and $g_{1}$ $=-\ln \left(r^{*}\right)$, where $r^{*}$ denotes the prior median of the distribution. In this case, $g_{1}=-\ln (0.80)$, which is consistent with the belief that under a competitive market farms must be close to the frontier (i.e., full efficiency; van den Broeck et al., 1994). In addition, this value is in concordance with results of previous empirical work by Hadley 
(2006) on efficiency of dairy farms in England and Wales. In the empirical analysis for $j>1, e_{j}=g_{j}=1$, which implies relatively noninformative values that center the prior for $\varphi_{j}$ over 1 :

$$
p(\boldsymbol{\varphi})=\prod_{j=1}^{r} f_{G}\left(\boldsymbol{\varphi}_{j} \mid e_{j}, g_{j}\right)
$$

\section{The Joint Posterior}

Once the likelihood and the priors are defined, it is possible to obtain the joint posterior distribution, which defines the Bayesian model:

$$
p\left(\boldsymbol{\beta}, h, \mu_{z}, \mathbf{z} \mid \mathbf{y}\right)=p\left(\mathbf{y} \mid \boldsymbol{\beta}, h, \mu_{z}^{-1}, \mathbf{z}\right) \times p(\boldsymbol{\beta}) \times p(h) \times p\left(\mathbf{z} \mid \mu_{z}^{-1}(\boldsymbol{\varphi})\right) \times p(\boldsymbol{\varphi}) .
$$

\section{The Conditional Posteriors}

The conditional posterior for an informative $\boldsymbol{\beta}$ is a normal distribution:

$$
p\left(\boldsymbol{\beta} \mid h, \mu_{z,}^{-1}, \mathbf{z}, \mathbf{y}\right) \sim N(\overline{\boldsymbol{\beta}}, \overline{\mathbf{V}}) .
$$

The conditional posterior density for $h$ is

$$
p\left(h \mid \boldsymbol{\beta}, \mu_{z,}^{-1}, \mathbf{z}, \mathbf{y}\right) \sim G\left(\bar{s}^{-2}, \bar{v}\right) .
$$

As pointed out above for the inefficiencies a hierarchical prior is used. The conditional posterior for $\varphi$ is proportional to the product of $p\left(z \mid \mu_{z}^{-1}(\varphi)\right)$ and $p(\varphi)$. As pointed out by Koop et al. (1997) the fact that $w_{i j}$ are $0-1$ dummy variables simplifies the conditional posterior for $\varphi$. This conditional posterior has a Gamma form:

$$
p\left(\boldsymbol{\varphi}_{j} \mid \mathbf{y}, \boldsymbol{\beta}, h, \mu_{z}^{-1}(\boldsymbol{\varphi}), \mathbf{z}\right)=f_{G}\left(\boldsymbol{\varphi}_{j} \mid e_{j}+\sum_{i=1}^{N} w_{i j}, g_{j}+\sum_{i=1}^{N} w_{i j} z_{i} \prod_{s \neq j} \boldsymbol{\varphi}_{s}^{w_{i s}}\right),
$$

and the conditional posterior for $z_{i}$

$$
p\left(z_{i} \mid \boldsymbol{\beta}, h, \mu_{z}^{-1}(\boldsymbol{\varphi}), \mathbf{y}\right) \propto \exp \left[-\frac{h T}{2}\left[z_{i}-\overline{\mathbf{x}}_{i} \boldsymbol{\beta}+\bar{y}_{i}+\frac{\mu_{z}^{-1}(\boldsymbol{\varphi})}{T h}\right]^{2}\right] I(\mathbf{z} \geq 0),
$$

where $\overline{\mathbf{x}}_{i}=\sum_{t=1}^{T} \frac{x_{i, t}}{T}, \bar{y}_{i}=\sum_{t=1}^{T} \frac{y_{i, t}}{T}$, and $I$ is an indicator function that equals 1 if $\mathbf{z}$ is larger or equal to 0 and equals 0 otherwise. As pointed out above, a hierarchical prior is used for the inefficiencies. This means that the mean of the inefficiency distribution is treated as a parameter, which requires its own prior, as in Koop (2003). 